\title{
Fitase e seus efeitos extrafosfóricos em dietas para frangos de corte: revisão
}

\author{
Jomara Broch', Gabriela Glaeser Sangalli², Vaneila Daniele Lenhardt Savaris ${ }^{3}$ e Ricardo Vianna Nunes ${ }^{4}$
}

\begin{abstract}
Resumo - As dietas para aves são compostas principalmente por produtos de origem vegetal, sendo que a maior parte do fósforo (P) se encontra na forma indisponível, denominada fitato. A molécula de fitato e os nutrientes ligados a ela não podem ser absorvidos no trato digestivo sem degradação enzimática realizada pelas fitases. As fitases hidrolisam o fitato em uma molécula de inositol e seis moléculas inorgânicas de fosfato reduzindo os seus efeitos antinutricionais. A magnitude da resposta da fitase pode ser mais significativa com o aumento dos níveis de inclusão. A degradação do fitato se correlaciona com grandes aumentos na retenção de $\mathrm{P}$, concentração de cinzas na tíbia, ganho de peso, consumo de ração, eficiência alimentar, retenção de nitrogênio, energia metabolizável aparente e retenção de Ca. Por isso, esta revisão tem o objetivo de caracterizar a fitase e abordar os aspectos relacionados com sua eficácia e seus efeitos extrafosfóricos em dietas para frangos de corte.
\end{abstract}

Termos para indexação: desempenho; enzimas exógenas; fósforo inorgânico

\section{Phytase and its extraphosphoric effects in broiler diets: review}

\begin{abstract}
Broiler's diets are mainly composed of plant origin products, where most of the phosphorus $(P)$ is in the unavailable form, called phytate. The phytate molecule and the nutrients attached to it cannot be absorbed in the digestive tract without enzymatic degradation by the phytases. Phytases hydrolyze phytate in one molecule of inositol and six inorganic phosphate molecules reducing their antinutritional effects. The magnitude of phytase response may be more significant with increasing inclusion levels and phytate degradation correlates with large increases in $\mathrm{P}$ retention, tibia ash concentration, weight gain, feed intake, feed efficiency, retention of nitrogen, apparent metabolizable energy and Ca retention. Therefore, this review has the objective of to characterize phytase and to address aspects related to its efficacy and its extra phosphoric effects in diets for broilers.
\end{abstract}

Index terms: performance, exogenous enzyme, inorganic phosphorus

\section{Introdução}

Entre os nutrientes essenciais para nutrição animal, o fósforo $(P)$ é um dos principais elementos e o mais oneroso ( 2 a $3 \%$ do custo total) a ser incluído na dieta. Este elemento é fundamental no metabolismo e no desenvolvimento das aves, exerce papel fisiológico importante no organismo e possui relação direta com a saúde e o desenvolvimento das aves e dos ossos. Além disso, está relacionado a sérios problemas ambientais quando depositado de maneira imprópria na natureza, sendo considerado um dos principais poluentes da água e do solo (MUNIR \& MAQSOOD, 2013).
As dietas para aves são compostas principalmente por produtos de origem vegetal, nos quais a maior parte do $P$ se encontra na forma indisponível, denominada fitato; em torno de 2,5 a 4,0g $\mathrm{kg}^{-1}$ (RAVINDRAN, 1995). O fitato possui baixa solubilidade no intestino delgado, sendo mal absorvido pelas aves e sua carga negativa o confere a capacidade de formar quelatos, produzindo sais insolúveis com minerais, que reduzem a digestibilidade dos nutrientes da dieta (WILKINSON et al., 2014).

Visto que a maior parte do $\mathrm{P}$ contido nos alimentos utilizados nas dietas para aves se encontra na forma indisponível, fontes inorgânicas são utilizadas para fornecer as exigências deste mineral. No entanto, estas possuem um alto custo e provêm de fontes não renováveis. Para aumentar a disponibilidade do $\mathrm{P}$ fítico, a fitase é adicionada às rações, possibilitando uma hidrólise eficaz.

Fatores como a relação cálcio (Ca): P da dieta, a proporção em relação a outros minerais, a concentração de aminoácidos e a vitamina $D$ podem influenciar a absorção do $P$ (ADEDOKUN \& ADEOLA, 2013). Além disso, o tipo de dieta, a fonte e a quantidade de ácido fítico, aliados ao tipo de fitase presente nos ingredientes utilizados, também podem interferir na utilização e no aproveitamento do $\mathrm{P}$ pelas aves.

Recebido em 24/5/2019. Aceito para publicação em 27/8/2019.

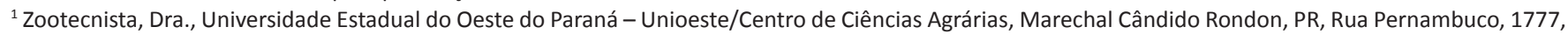
CEP: 85960-000, e-mail: brochjomara@yahoo.com.br.

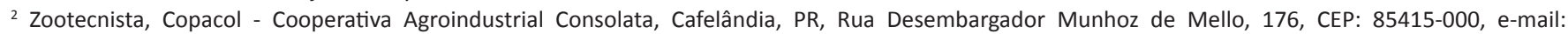
gabrielasangalli@hotmail.com.

${ }^{3}$ Zootecnista, Msc. Tectron - Tecnologia e Inovação, Toledo, PR, Av. Maripá, 895, CEP 85908-220, e-mail: vaneilalenha@hotmail.com

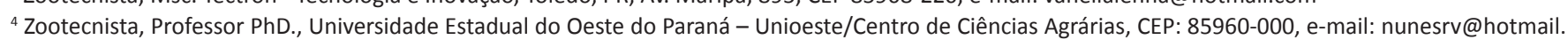
com 
A molécula de fitato e os nutrientes ligados a ela não podem ser absorvidos no trato digestivo sem degradação enzimática realizada pelas fitases (GUPTA et al., 2015). As fitases são as enzimas exógenas mais utilizadas em dietas comerciais para animais não ruminantes e caracterizam-se por reduzir os efeitos antinutricionais do fitato. Elas são capazes de disponibilizar o $\mathrm{P}$ que ocorre naturalmente na forma de fitato e, assim, reduzir a quantidade de $P$ inorgânico suplementado na dieta e também meIhorar a disponibilidade de outros minerais, de aminoácidos e energia. Além disso tudo, as fitases contribuem para reduzir o impacto negativo da excreção de $\mathrm{P}$ inorgânico no ambiente (MUNIR \& MAQSOOD, 2013).

Objetivou-se com esta revisão caracterizar a fitase e abordar os aspectos relacionados à sua eficácia e seus efeitos extrafosfóricos em dietas para frangos de corte.

\section{Revisão}

\section{Ácido fítico}

O ácido fítico é um ácido livre, essencial durante a germinação das sementes e responsável por suprir as necessidades de biossíntese dos tecidos em crescimento das plantas. Os sais do ácido fítico, descritos como fitatos, correspondem a uma mistura de minerais, como potássio, magnésio e cálcio, presentes como quelato e armazenados na forma de fósforo $(P)$ em cereais, legumes e óleos (PALLAUF \& RIMBACH, 2009).

O teor de ácido fítico e a disponibilidade do $P$ para os animais é altamente variável (Tabela 1). Esta variabilidade pode depender das condições de crescimento da planta, do tamanho das partículas e dos processos tecnológicos utilizados no beneficiamento dos cereais (TAHIR et al., 2012), além dos métodos utilizados para sua determinação. Sementes oleaginosas, grãos integrais e leguminosas representam as fontes mais concentradas, já raízes, tubérculos e outros vegetais geralmente apresentam quantidades mais baixas. Na maioria dos grãos o fitato é isolado na camada de aleurona, o que o torna mais con-

Tabela 1. Fósforo total, fítico e disponível nos ingredientes Table 1. Total phosphorus, phytic and available in ingredients

\begin{tabular}{lccc}
\hline Ingredientes & P total (\%) & P fítico (\%) & P disponível (\%) \\
\hline Arroz, farelo & 1.71 & 1.37 & 0.35 \\
\hline Aveia, grão & 0.38 & 0.16 & 0.22 \\
\hline Canola, farelo & 1.14 & 0.75 & 0.39 \\
\hline Carne e ossos, farinha (48\%) & 5.79 & - & 5.21 \\
\hline Cevada, grão & 0.35 & 0.20 & 0.15 \\
\hline Mandioca, integral raspa & 0.08 & 0.06 & 0.02 \\
\hline Milho, grão (7,86\%) & 0.24 & 0.18 & 0.06 \\
\hline Milho, glúten (60\%) & 0.52 & 0.47 & 0.05 \\
\hline Penas e vísceras, farinha & 1.15 & - & 1.15 \\
\hline Soja, farelo (45\%) & 0.55 & 0.36 & 0.19 \\
\hline Trigo, farelo & 0.94 & 0.45 & 0.49 \\
\hline Trigo, grão & 0.32 & 0.22 & 0.10 \\
\hline
\end{tabular}

Fonte: Rostagno et al. (2017)

centrado no farelo; já nas leguminosas é encontrado na camada de cotilédone (NISSAR et al., 2017).

O fitato é carregado negativamente nas diversas condições de pH (ácido, neutro e básico). Isso lhe confere a capacidade de se precipitar com as moléculas carregadas positivamente da dieta, secreções endógenas do trato gastrointestinal e a proteína dietética, formando complexos resistentes à hidrólise. Desta forma, a digestibilidade dos nutrientes da digesta é reduzida, causando a utilização incompleta destas substâncias pelos animais (WOYENGO \& NYACHOTI, 2013). A capacidade de ligação dos grupos de fosfato a cátions é afetada pela sua distribuição no anel de mio-inositol; os complexos são mais solúveis com a redução e mais fracos com a remoção dos grupos de fosfato (NISSAR et al., 2017).

As dietas típicas de frangos de corte contêm em torno de 2,5 a 4,0g de fitato $\mathrm{kg}^{-1}$. Para que o $\mathrm{P}$ seja utilizado, o fitato deve ser hidrolisado de forma que os íons de fosfato inorgânico sejam liberados, o que dependerá da capacidade enzimática das aves. A degradação do fitato no trato digestivo das aves pode ser atribuída a uma ou mais fitases e elas são possíveis através de três fontes: fitases da secreção digestiva intestinal; atividade de fitase proveniente de bactérias residentes ou atividade da fitase endógena presente em alguns ingredientes (RAVINDRAN, 1995).

\section{Mecanismos de atuação das fitases}

As fitases hidrolisam o fitato em uma molécula de inositol e seis moléculas inorgânicas de fosfato. Assim, se o fitato é hidrolisado, em seguida os seus efeitos antinutricionais são reduzidos, podendo ser utilizado pelas aves (RAVINDRAN, 1995). A suplementação de fitase em dietas de aves é uma prática comum utilizada em larga escala e muito importante devido à atividade inadequada da fitase endógena do trato digestivo das aves. A fitase melhora a utilização do $P$ fítico e reduz a excreção de $P$ no ambiente, e isto atrai um grande interesse científico e comercial (MUNIR \& MAQSOOD, 2013).

Na nutrição animal, as enzimas exógenas são responsáveis por degradar fatores antinutricionais presentes em muitos ingredientes da ração, aumentar a disponibilidade de alguns nutrientes, complementar as enzimas produzidas por animais jovens que, devido à imaturidade do sistema digestivo, têm produção insuficiente. Além disso, elas costumam reduzir a grande variabilidade nos valores nutritivos dos alimentos, melhorando assim a precisão nas formulações de rações (MUNIR \& MAQSOOD, 2013).

É importante que as enzimas utilizadas sejam específicas ao substrato disponível para que possam agir com eficiência. Por exemplo, o ambiente considerado ideal deve ser aquoso, pois a umidade é essencial para a mobilidade 
e a solubilidade da enzima e do substrato; altas temperaturas podem resultar em desnaturação e redução da atividade enzimática e a relação substrato vs. enzima deve ser adequada, sendo que, quanto mais substrato, melhor e maior a área de atuação para a enzima (RAVINDRAN, 2013).

A relação substrato vs. enzima está associada com a eficácia da enzima. A partir daí é importante considerar que a presença de substratos nos ingredientes é bastante variável e dependente da localização desse substrato na matriz do ingrediente, da presença de outros possíveis fatores antinutricionais e da diferença na acessibilidade ou solubilidade da enzima (OLUKOSI, 2013).

A hidrólise do fitato em ortofosfato e fosfatos de inositol é conseguida enzimaticamente com fitase. Este método reduz o conteúdo de ácido fítico nos grãos, sem reduzir o seu conteúdo mineral (GUPTA et al., 2015). A fitase (mioinositol 1,2,3,4,5,6 - hexaquis fosfato fosfoidrolases) é a única enzima conhecida que pode iniciar a desfosforilação gradual do fosfato no carbono 1, 3 ou 6 no anel inositol do fitato, gerando uma série de ésteres fosfatos mio-inositol inferiores (IP 6 IP 5 IP 4 IP 3 IP 2 IP 1). Através dessa sucessão de reações de desfosforilação, são produzidos seis radicais de $P$ inorgânico e inositol (SELLE \& RAVINDRAN, 2007), além da liberação de cálcio, ferro, zinco e outros metais.

As fitases podem ser divididas em três grupos: com base no mecanismo catalítico, tem-se as fitases dos ácidos histidina, de cisteína ou ácido roxo; com base no $\mathrm{pH}$, dividem-se em fitases ácidas e alcalinas; e também com base no carbono no anel de mio-inositol de fitato em que a desfosforilação é iniciada, em 3-fitases (EC 3.1.3.8), 6-fitases (CE 3.1.3.26) e 5-fitases (EC. 3.1.3.72) (GREINER \& KONIETZNY, 2006).

$A$ atividade da fitase foi detectada em muitas espécies de plantas, como trigo, centeio, cevada, ervilha, feijão, soja, milho, arroz, alface, espinafre, grama, pólen de lírio, etc., mas como o processo de produção a partir de plantas é oneroso e demorado, a produção de fitase de origem microbiana é a mais desenvolvida (GUPTA et al., 2015).

$A$ atividade de fitase é expressa em
FTU, que corresponde à quantidade de fitase que libera $1 \mathrm{~mol}$ de fosfato inorgânico por minuto a partir de $0,0051 \mathrm{~mol}$ $\mathrm{L}^{-1}$ fitato de sódio em $\mathrm{pH}$ de 5,5 e a uma temperatura de $37^{\circ} \mathrm{C}$ (AOAC, 2000). Contudo, em termos práticos, a especificação padrão de mensuração estabelecida para a atividade de fitase é diferente das condições reais in vivo dos animais e, além disso, muitas características associadas à composição da dieta e características dos animais podem influenciar a atividade da enzima in vivo.

A atuação da fitase está relacionada às características ligadas aos animais (espécie, idade, condições fisiológicas), aos fatores dietéticos (concentração e fonte de fitato, e minerais), à origem e ao nível da fitase adicionada à dieta (DERSJANT-LI et al., 2015). O nível dietético de fósforo $(P)$ também pode influenciar na resposta da fitase. Por isso, níveis muito altos ou baixos devem ser evitados; altos níveis de Ca ou alta relação Ca: $P$ pode reduzir a resposta da fitase; e a vitamina $D$ exerce influência indireta na atividade da fitase através do aumento da absorção de $\mathrm{Ca}$, limitando a formação de fitatos de Ca insolúveis, resistentes à hidrólise da enzima (KORNEGAY, 2001).

Propriedades como estabilidade, resistência à protease, inativação pelo $\mathrm{HCl}$ no estômago e a origem da enzima são essenciais para a ação eficiente das fitases na alimentação dos animais (OLUSKI, 2013). Outro aspecto importante é o local da atividade de diferentes tipos de fitases no trato digestório do animal; pesquisas sugerem que a parte superior do trato digestivo é o principal local.

O nível do pH no estômago das aves está entre 2,5 a 3,5; ou seja, valores muito abaixo de 5,5 , considerado o valor da mensuração padrão da atividade da fitase. Portanto, a atividade "real" in vivo é muito variável. Como o ácido fítico (e fitato) dissocia-se e é solúvel em pH ácido (por exemplo, estômago), a formação dos minerais e dos complexos ocorre principalmente em $\mathrm{pH}$ mais elevado, como o do intestino. Assim, os ácidos fíticos se complexam com cálcio, proteínas e aminoácidos, além de interagirem com enzimas endógenas, resultando na redução da digestibilidade dos nutrientes (DERSJANT-LI et al., 2015).
Deste modo, uma hidrólise prévia do fitato pela fitase na parte superior do trato digestivo é essencial para uma meIhora na digestibilidade dos nutrientes, pois isso resultará em uma molécula de inositol e seis moléculas inorgânicas de fosfato (mais aminoácidos, minerais entre outros nutrientes). Em casos de uma hidrólise incompleta, normalmente pode restar IP4 e IP3, que são muito resistentes ao ataque das fitases. Assim, o sucesso de altas doses de fitase depende da sua especificidade ao substrato e também da destruição destes ésteres de fosfatos remanescentes e da geração do inositol através do esforço conjunto da fitase exógena e das fosfatases da mucosa.

\section{Suplementação de fitase em dietas para frangos de corte: efeitos extrafos- fóricos}

A fitase tem sido utilizada para reduzir o custo da dieta através da possibilidade de redução de fontes de fosfato inorgânico, energia, calcário e aminoácidos sintéticos. Esses efeitos estão ligados a uma matriz de liberação de nutrientes para uma determinada dose da enzima e o valor criado dependerá dos preços dos vários nutrientes deslocados (COWIESON et al., 2015). Antigamente, utilizava-se uma dose fixa de 500FTU $\mathrm{kg}^{-1}$ em ração de frangos, por exemplo, mas com os avanços das pesquisas, e devido a fatores econômicos, é grande o interesse do uso de doses mais elevadas.

Um pré-requisito para a formulação de rações é a equivalência do $P$ da fitase, no entanto, este valor ainda não está bem definido. Os valores para equivalência da fitase são conflitantes e os critérios de resposta utilizados para avaliar estes valores possuem um efeito importante sobre os resultados. Segundo Selle \& Ravindran (2007), o valor geral determinado para a equivalência de $P$ da fitase (840FTU $\mathrm{kg}^{-1}=1.0 \mathrm{~g} \mathrm{~kg}$ P) não é exatamente o valor real sugerido na prática. Isto porque os resultados são afetados pelo teor e a fonte de $\mathrm{P}$, nível de $\mathrm{Ca}$, tipo de dieta, espécie e idade do animal (animais jovens tendem a responder melhor às enzimas do que animais mais velhos) (ANSELME, 2006); 
além do tipo e a quantidade de cereais, os fatores antinutricionais e as enzimas utilizadas (MUNIR \& MAQSOOD, 2013).

A magnitude da resposta da fitase pode ser mais significativa com o aumento dos níveis de inclusão nas dietas, provavelmente devido à maior degradação do fitato, pois quando este é hidrolisado os seus efeitos antinutricionais são eliminados (KORNEGAY, 2001). Além disso, a degradação do fitato se correlaciona positivamente com grandes aumentos na retenção de $P$, concentração de cinzas na tíbia, ganho de peso, consumo de ração, eficiência alimentar, retenção de nitrogênio, energia metabolizável aparente e retenção de Ca; resultados que são mais pronunciados com altos níveis de inclusão (SELLE \& RAVINDRAN, 2007).

Alguns resultados sugerem que 0 aumento dos níveis de $\mathrm{P}$ dietético pode impedir as respostas ao aumento dos níveis de inclusão de fitase. E existem duas explicações para isso: o produto final da hidrólise do fitato, o P inorgânico, inibe a atividade catalítica da fitase (LEI \& STAHL, 2000); e o aumento da liberação de $\mathrm{P}$, devido à ação da fitase, pode provocar um desequilíbrio entre o Ca e $P$ no trato gastrointestinal do animal. Outra explicação é que altos níveis de fitase podem alterar o balanço eletrolítico da dieta, pois o fitato e a fitase influenciam a secreção de sódio no lúmen intestinal (RAVINDRAN et al., 2013).

Altas doses de fitase podem ser benéficas, mas é necessário adequar os níveis de nutrientes e os demais fatores dietéticos para que as vantagens sejam perceptíveis (SELLE \& RAVINDRAN, 2007). Também é preciso considerar que a atuação da fitase está relacionada às características ligadas ao animal (espécie, idade, condições fisiológicas), aos fatores dietéticos (concentração e fonte de fitato, concentração de minerais) e à origem e nível da enzima adicionada à dieta (DERSJANT-LI et al., 2015). Também é muito importante escolher o modelo apropriado, pois os dados se ajustam melhor a um modelo específico, então eles podem fornecer estimativas diferentes dos níveis de uso que maximizam os lucros (BEDFORD et al., 2016).

Em estudo realizado por Boney \& Moritz (2017), com frangos de corte, os autores constataram melhora na conversão alimentar e aumento da disponibilidade de $P$, além de influências benéficas na saúde intestinal, possivelmente devido a uma redução da irritação do intestino. Os autores especulam que a eficácia da fitase pode ser afetada dependendo da composição dos ingredientes utilizados e da presença de fatores antinutricionais.

Ao avaliar se a eficácia da fitase poderia ser afetada por uma fonte de proteína da dieta, Kaczmarek et al. (2016) observaram que a fitase melhorou o ganho de peso corporal, a taxa de conversão alimentar e a deposição de $\mathrm{Ca}$ e $P$ nas tíbias, independentemente da fonte proteica. A melhora no conteúdo de cinzas, Ca e $\mathrm{P}$ na tíbia indica um aumento na mineralização óssea, referente ao aumento na disponibilidade de minerais liberados pela fitase a partir do complexo mineral do fitato. A desfosforilação do ácido fítico pela fitase provavelmente levou a uma melhor mineralização óssea via maior digestibilidade ileal do Ca e P. Ainda, segundo os autores, é possível que ocorram variações na degradação do fitato em diferentes ingredientes, dependendo da localização dos fitatos, o que pode torná-los mais resistentes ao ataque direto da fitase. A eficácia da fitase sobre a digestibilidade dos aminoácidos também parece depender do ingrediente utilizado na dieta, estando ligada ao tipo e concentração da proteína. Vale ressaltar que proteínas formam complexos insolúveis com ácido fítico em $\mathrm{pH}$ baixo, como já reportado em diversas literaturas.

Os resultados encontrados por Cowieson et al. (2015) em experimentos realizados com frangos de corte recebendo altas doses de fitase apontaram melhora no desempenho, aumento na retenção de $C$ a e $P$, resistência da tíbia, teor de cinzas e concentrações de inositol no plasma. Os resultados sugeriram que o efeito benéfico de altas doses de fitase pode ser conferido através de mecanismos similares ao da insulina e que os efeitos da fitase são eficazes na meIhoria do desempenho das aves alimentadas com dietas com níveis adequados ou não de Ca e P.

Os efeitos da fitase sobre as propriedades histológicas, mecânicas e quími- cas da tíbia também foram avaliados por Qian et al. (1996). No experimento foi observado que a deficiência do $P$ influenciou o grau de conversão da cartilagem em osso e a ordem do desenvolvimento histológico da tíbia, provocando uma mineralização defeituosa ou desorganizada da matriz extracelular da zona de cartilagem hipertrófica. Já as melhoras das características histológicas da tíbia ocorreram devido à suplementação de fitase e de P inorgânico; as tíbias foram mais longas e largas e houve uma melhora na força de ruptura, ou seja, ocorreu uma melhor mineralização óssea. Além dos benefícios sobre as características ósseas, a fitase melhorou o ganho de peso corporal e o consumo de ração. Os resultados sugerem que a fitase melhora a qualidade da dieta por meio da liberação de outros minerais e nutrientes, além de aumentar a disponibilidade de $\mathrm{P}$ e promover o crescimento e desenvolvimento dos ossos. Assim, a quantidade de $\mathrm{P}$ inorgânico adicionado pode ser reduzida.

As informações sobre os efeitos da fitase em dietas com redução nutricional sobre rendimentos e características de qualidade de carcaça ainda são limitadas. Os resultados do trabalho realizado por Driver et al. (2006) indicaram que dietas com deficiência de Ca e $\mathrm{P}$, durante as fases inicial e final, afetam a integridade dos diferentes ossos das aves de diferentes maneiras durante o abate e o processamento. A resistência de ruptura da tíbia e fêmur (ossos longos) parece ser influenciada pelo conteúdo de Ca e $\mathrm{P}$ de dietas iniciais, pois é nesta fase que o desenvolvimento ósseo é mais ativo; enquanto a incidência de clavículas (osso curto) com ruptura foi influenciada apenas pelo tipo de dieta durante a fase final, pois é mais sensível a flutuações nos níveis de Ca e P a curto prazo. Assim, concluiu-se que a qualidade da carcaça depende dos níveis de $\mathrm{Ca}$ e $P$ e também da idade da ave.

Além de todos os benefícios supracitados, a fitase é apontada como responsável pelo aumento da digestibilidade do $P$ e pela redução da excreção fecal de P. Isso é muito importante, uma vez que os resíduos de fosfatos dos animais representam um grande problema ambiental, pois são contaminantes de 
reservatórios de água, através do escoamento superficial ou da lixiviação (SELLE \& RAVINDRAN, 2007; MUNIR \& MAQSOOD, 2013).

\section{Considerações finais}

A adição de fitases em dietas para aves proporciona benefícios produtivos, como a melhora do desempenho e a redução da mortalidade. A prática também possibilita ao nutricionista maior flexibilidade na escolha do tipo de matérias-primas a serem utilizadas nas formulações de rações. Além disso, tem papel importante na redução do impacto negativo ambiental da produção animal sobre o ambiente, através da colaboração na redução da produção de resíduos.

\section{Referências bibliográficas}

ADEDOKUN, S.A.; ADEOLA, O. Calcium and phosphorus digestibility: Metabolic limits. Journal Applied Poultry Research, Champaign, v.22, n.3, p 600-608, 2013.

AOAC, Method 2000.12: Phytase activity in feed: colorimetric enzymatic method, in Official Methods of Analysis of AOAC International (17th edn). Association of Official Analytical Chemists, Arlington, VA (2000).

ANSELME, P. 2006. Considerations on the use of microbial phytase. CEFIC. Inorganic Feed Phosphates, Brussels.

BEDFORD, M.R.; CHOCT, M.; O'NEILL, H.M. Nutrition Experiments in Pigs and Poultry: A Practical Guide. In; Pesti, G.M.; Althon, R.A.; Da Costa, M.J.; Billard, L. Most common designs and understanding their limits. Boston: CABI, 2016. 178p.

BONEY, J.W.; MORITZ, J.S. Phytase dose effects in practically formulated diets that vary in ingredient composition on feed manufacturing and broiler performance. Journal of Applied Poultry Research, Champaign, v.26, n.2, p.273-285, 2017.

COWIESON, A.J.; AURELI, R.; GUGGENBUHL, P.; FRU-NJI, F. Possible involvement of myoinositol in the physiological response of broilers to high doses of microbial phytase.
Animal Production Science, Clayton South, v.55, n.6, p.710-719, 2015.

DERSJANT-LI, Y.; AWATI, A.; SCHULZE, H.; PARTRIDGE, G. Phytase in non-ruminant animal nutrition: a critical review on phytase activities in the gastrointestinal tract and influencing factors. Journal of the Science of Food and Agriculture, v.95, n.5, p.878-896, 2015.

DRIVER, J.P.; PESTI, G.M.; BAKALLI, R.I.; EDWARDS JR., H.M. The effect of feeding calcium-and phosphorus-deficient diets to broiler chickens during the starting and growing-finishing phases on carcass quality. Poultry Science, Champaign, v.85, n. 11, p.1939-1946, 2006.

GUPTA, R.K.; GANGOLIYA, S.S.; Singh, N.K. Reduction of phytic acid and enhancement of bioavailable micronutrients in food grains. Journal of Food Science and Technology, Campinas, v.52, n.2, p.676-684, 2015.

GREINER, R. AND KONIETZNY, U. Phytase for food application. Food Technology and Biotechnology, Zagreb, v.44, n.2, p.123-140, 2006.

KACZMAREK, S.A.; COWIESON, A.J.; HEJDYSZ, M.; RUTKOWSKI, A. Microbial phytase improves performance and bone traits in broilers fed diets based on soybean meal and containing lupin meal. Animal Production Science, Clayton South, v.56, n.10, p.1669-1676, 2016.

KORNEGAY, E.T. Digestion of phosphorus and other nutrients: the role of phytases and factors influencing their activity. Enzymes in farm animal nutrition, 2001. 237271p.

LEI, X.G.; STAHL, C.H. Nutritional benefits of phytase and dietary determinants of its efficacy. Journal of Applied Animal Research, Champaign, v.17, n.1, p.97-112, 2000.

MUNIR, K.; MAQSOOD, S. A review on role of exogenous enzyme supplementation in poultry production. Journal of Food and Agriculture, Abu Dhabi, v.25, n.1, p.66-80, 2013.

NISSAR, J.; AHAD, T.; NAIK, H.R.; HUSSAIN,
S.Z. A review phytic acid: As antinutrient or nutraceutical. Journal of Pharmacognosy and Phytochemistry, Rohini, v.6, n.6, p.1554-1560, 2017.

OLUKOSI, O.A. Biochemistry of phytate and phytases: Applications in monogastric nutrition. Journal of the Nigerian Society for Experimental Biology, Makhanda, v.24, n.2, p.58-63, 2013.

PALLAUF, J.; RIMBACH, G. Nutritional significance of phytic acid and phytase. Archives of Animal Nutrition, v.50, n.4, p.301-319, 1997.

QIAN, H., VEIT, H.P., KORNEGAY, E.T., RAVINDRAN, V., AND DENBOW, D.M. Effects of supplemental phytase and phosphorus on histological and other tibial bone characteristics and performances of broilers fed semipurified diets. Poultry Science, v.75, p.618626, 1996.

RAVINDRAN, V. Phytases in poultry nutrition. An overview. Poultry Science, Champaign, v.7, p.135-139, 1995.

RAVINDRAN, V. Feed enzymes: The science, practice, and metabolic realities. Journal of Applied Poultry Research, Champaign, v.22, n.3, p.628-636, 2013.

SELLE, P.H.; RAVINDRAN, V. Microbial phytase in poultry nutrition. Animal Feed Science and Technology, Davis, v.135, n.1, p.141, 2007.

TAHIR, M.; SHIM, M.Y.; WARD, N.E.; SMITH, C.; FOSTER, E.; GUNEY, A.C.; PESTI, G.M. Phytate and other nutrient components of feed ingredients for poultry. Poultry Science, Champaign, v.91, n.4, p.928-935, 2012.

WILKINSON, S.J.; SELLE, P.H.; BEDFORD, M.R.; COWIESON, A. J. Separate feeding of calcium improves performance and ileal nutrient digestibility in broiler chicks. Animal Production Science, Clayton South, v.54, n.2, p.172-178, 2014.

WOYENGO, T.A; NYACHOTI, C.M. Review: Anti-nutritional effects of phytic acid in diets for pigs and poultry-current knowledge and directions for future research. Canadian Journal of Animal Science, Ottawa, v.93, n.1, p.9-21, 2013. 